\title{
Quality Evaluation of World's Top 40 Universities Based on
}

\section{Multivariate Analysis}

\section{Mengran Yuan}

University of Southampton, Haidian District, Beijing, 100044, China

\begin{abstract}
University comprehensive quality evaluation is an important method to evaluate the quality of World University. Scoring on a university via the study and research of all aspects of a university, is an ideal way to show the whole picture of a university, that is, its quality level is built on the comprehensive evaluation of all aspects. Sampling on 40 world universities' quality evaluation data in 2005 , with six indicators as variables, including Score on Alumni (equivalent to the number of Nobel prize and the Fields prize awarded alumni), Score on Award(equivalent to the number of Nobel prize and the Fields prize for teachers), Score on HiCi (The number of faculty who have been cited the highest in each subject area), Score on N\&S (The number of papers published in the magazine), Score on SCI (Number of papers indexed by the Science Citation Index and the Social Science Citation Index), and Score on Size (the teachers' mean value of above five indicators), this study takes use of SAS statistical software for cluster analysis. Based on its classification result, this software is used again to carry out discriminant analysis for deeper evaluation of the comprehensive quality of these universities and generate typical correlation analysis to evaluate the reasonability of the indicators.
\end{abstract}

Keywords: University Quality, Cluster Analysis, Discriminant Analysis, Typical Correlation Analysis,

\section{Ranking of world's top 40 universities}

The comprehensive quality evaluation data of the world's top 40 universities in 2005 is shown in table 1:

\begin{tabular}{l|c|c|c|c|c|c|c}
\hline Code & University & $\begin{array}{c}\text { Score } \\
\text { on } \\
\text { Alumni }\end{array}$ & $\begin{array}{c}\text { Score } \\
\text { on } \\
\text { Award }\end{array}$ & $\begin{array}{c}\text { Score } \\
\text { on } \\
\text { HiCi }\end{array}$ & $\begin{array}{c}\text { Score } \\
\text { on N\&S }\end{array}$ & $\begin{array}{c}\text { Score } \\
\text { on } \\
\text { SCI }\end{array}$ & $\begin{array}{c}\text { Score } \\
\text { on } \\
\text { Size }\end{array}$ \\
\hline 1 & Harvard Univ & 100 & 100 & 100 & 100 & 100 & 72.4 \\
\hline 2 & Univ Cambridge & 99.8 & 93.4 & 53.3 & 56.6 & 70.9 & 66.9 \\
\hline 3 & Stanford Univ & 41.1 & 72.2 & 88.5 & 70.9 & 72.3 & 65 \\
\hline 5 & Univ California - & 71.8 & 76 & 69.4 & 73.9 & 72.2 & 52.7 \\
\hline 6 & Berkeley & 74 & 80.6 & 66.7 & 65.8 & 64.3 & 53 \\
\hline
\end{tabular}


Table 1, cont.

\begin{tabular}{|c|c|c|c|c|c|c|c|}
\hline 7 & Columbia Univ & 79.4 & 60.6 & 56.1 & 54.2 & 69.5 & 45.4 \\
\hline 8 & Princeton Univ & 63.4 & 76.8 & 60.9 & 48.7 & 48.5 & 59.1 \\
\hline 9 & Univ Chicago & 75.6 & 81.9 & 50.3 & 44.7 & 56.4 & 42.2 \\
\hline 10 & Univ Oxford & 64.3 & 59.1 & 48.4 & 55.6 & 68.4 & 53.2 \\
\hline 11 & Yale Univ & 52.1 & 44.5 & 60.3 & 57.2 & 63.9 & 49.3 \\
\hline 12 & Cornell Univ & 46.5 & 52.4 & 55 & 48.8 & 66.3 & 39.8 \\
\hline 13 & $\begin{array}{c}\text { Univ California - } \\
\text { San Diego }\end{array}$ & 17.7 & 34.7 & 59.8 & 56.5 & 64.5 & 46.6 \\
\hline 14 & $\begin{array}{l}\text { Univ California - } \\
\text { Los Angeles }\end{array}$ & 27.3 & 32.8 & 56.7 & 50.1 & 75.6 & 34.3 \\
\hline 15 & Univ Pennsylvania & 35.5 & 35.1 & 56.7 & 42.9 & 71.8 & 39.1 \\
\hline 16 & $\begin{array}{c}\text { Univ Wisconsin - } \\
\text { Madison }\end{array}$ & 43 & 36.3 & 52.1 & 46.3 & 68.7 & 29 \\
\hline 17 & Univ Washington - Seattle & 28.8 & 32.4 & 53.9 & 47.1 & 73.8 & 27.2 \\
\hline 18 & $\begin{array}{l}\text { Univ California - } \\
\text { San Francisco }\end{array}$ & 0 & 37.6 & 55.6 & 57.9 & 58.8 & 45.2 \\
\hline 19 & Johns Hopkins Univ & 51.4 & 28.3 & 41.6 & 52.2 & 67.7 & 24.9 \\
\hline 20 & Tokyo Univ & 36 & 14.4 & 38.5 & 52.1 & 86.5 & 34.7 \\
\hline 21 & $\begin{array}{c}\text { Univ Michigan - } \\
\text { Ann Arbor }\end{array}$ & 43 & 0 & 61.9 & 43 & 76.5 & 30.9 \\
\hline 22 & Kyoto Univ & 39.7 & 34.1 & 34.2 & 37 & 72.3 & 31.1 \\
\hline 23 & Imperial Coll London & 20.8 & 38.1 & 40.8 & 38.2 & 64.6 & 40.3 \\
\hline 24 & Univ Toronto & 28.1 & 19.7 & 39.3 & 38.9 & 76.7 & 41.9 \\
\hline 25 & $\begin{array}{c}\text { Univ Illinois - } \\
\text { Urbana Champaign }\end{array}$ & 41.6 & 37.4 & 44.4 & 34.1 & 58 & 26 \\
\hline 26 & Univ Coll London & 30.7 & 32.9 & 37.7 & 41.5 & 60.5 & 38.8 \\
\hline 27 & $\begin{array}{l}\text { Swiss Fed Inst } \\
\text { Tech - Zurich }\end{array}$ & 40.2 & 37 & 35.1 & 41.1 & 43.4 & 52.4 \\
\hline 28 & $\begin{array}{c}\text { Washington Univ - St. } \\
\text { Louis }\end{array}$ & 25.1 & 26.6 & 38.5 & 46.5 & 53.9 & 39.9 \\
\hline 29 & New York Univ & 33.8 & 25 & 43 & 35.3 & 55.4 & 26.3 \\
\hline 30 & Rockefeller Univ & 22.6 & 59.8 & 28.3 & 44.1 & 24 & 35.9 \\
\hline 31 & Northwestern Univ & 21.7 & 19.3 & 44.4 & 33.8 & 57.6 & 36.2 \\
\hline 32 & Duke Univ & 20.8 & 0 & 47.1 & 45.3 & 60.8 & 38.9 \\
\hline 33 & $\begin{array}{c}\text { Univ Minnesota - } \\
\text { Twin Cities }\end{array}$ & 36 & 0 & 49.7 & 35.2 & 68.4 & 23.8 \\
\hline 34 & $\begin{array}{c}\text { Univ California - } \\
\text { Santa Barbara }\end{array}$ & 0 & 36 & 42.3 & 39 & 44.1 & 35.8 \\
\hline 35 & Univ Colorado - Boulder & 16.6 & 29.8 & 40.8 & 36.6 & 46.3 & 29.5 \\
\hline 36 & Univ Texas - Austin & 21.7 & 17.1 & 49.1 & 30 & 54.8 & 21.7 \\
\hline 37 & Univ British Columbia & 20.8 & 19.3 & 32.4 & 32.5 & 60.4 & 33.9 \\
\hline
\end{tabular}


Table 1, cont.

\begin{tabular}{l|c|c|c|c|c|c|c}
\hline 8 & $\begin{array}{c}\text { Univ Texas } \\
\text { Southwestern } \\
\text { Med Center }\end{array}$ & 24.3 & 33.9 & 31.4 & 38.2 & 37.9 & 31 \\
\hline 39 & $\begin{array}{c}\text { Pennsylvania State Univ - } \\
\text { Univ Park }\end{array}$ & 14 & 0 & 45.8 & 37.9 & 59.9 & 24 \\
\hline 40 & Vanderbilt Univ & 12.5 & 30.2 & 34.2 & 24.5 & 49.2 & 35.6 \\
\hline
\end{tabular}

Table 1 Data Sheet of Comprehensive Quality Evaluation of 40 Universities in the World in 2005

\section{Clustering analysis}

\subsection{Group-average cluster method}

\subsubsection{Root mean square of the data}

The sample size is 40 , so the distance among the various universities is $C_{40}^{2}=780$, distance root mean square $=72.42767$. There are 38 clusters in this method, and the number of universities in each category varies from 2-40.

\subsubsection{Pseudo-F statistic}

$$
F=\frac{\left(W-P_{m}\right) /(m-1)}{P_{m} /(n-m)}
$$

Pseudo-F is used to evaluate clustering effects of m clusters. The larger the value of the pseudo-F statistic, the more distinctive $\mathrm{n}$ samples can be divided into $\mathrm{m}$ clusters. Pseudo-F statistics can be used as a useful indicator to determine the number of clusters. In this example, the normalized Euclidean distance between the first clusters is the smallest, and the maximum of pseudo-F statistic is 51.4 , and the pseudo-F is the minimum in last clustering.

\subsubsection{Pseudo- $t^{2}$ statistics}

PSeudot $^{2}=\frac{D_{K L}^{2}}{\left(W_{K}-W_{L}\right) /\left(n_{K}+n_{L}-2\right)}$

In this formula $D_{K L}^{2}=W_{M}-W_{K}-W_{L}$ is the new cluster $G_{M}$ increment of Sum of

Squared Deviations produced by the merging of combines Cluster $G_{K}$ with Combine 
Cluster $G_{L}$. Pseudo- $t^{2}$ is used to evaluate the effect of merging clusters $G_{K}$ and $G_{L}$. The larger the $t^{2}$, indicating after merging into new cluster $G_{M}$ by combining $G_{K}$ and $G_{L}$, the increment $D_{K L}^{2}$ is larger than the original sum of squared deviations of $G_{K}$ and $G_{L}$, which means that the two clusters are separated well, that is, the effect of the last cluster is good.

Pseudo $t^{2}$ statistics are useful indicators for determining the number of clusters. Pseudo $t^{2}$ is minimum in the first clustering. Analogy accordingly, the final clustering is the maximum clustering formed by the 39th universities' clustering with the first group clustering, and the standardized root mean square distance between them is the largest, and the pseudo $t^{2}$ is maximum, equals to 42.8 . The arborescence of the average clustering method is shown in figure 1.

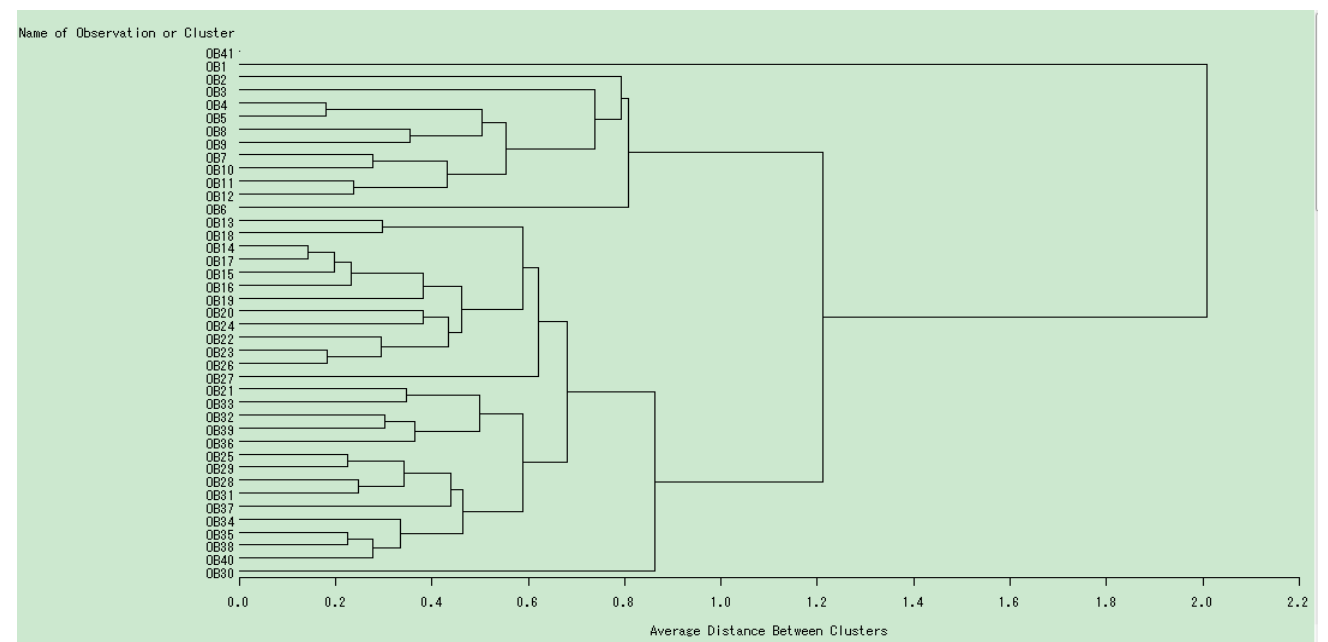

Figure 1 The arborescence produced under the average clustering method

\subsection{The shortest distance clustering method}

The shortest distance clustering method is similar to the group-average cluster method, while we just offer a brief analysis here.

\subsubsection{The average distance among observed values.}

From SAS analysis, the average distance of observed value between these 40 observations is 64.40822 . There are 39 clusters in this approach, with the number of universities in each group ranging from 2 to 40.

\subsubsection{Normal Min Distance (Norm Min Dist.).}

It can be seen from figure 2 that the shortest distance from the top to the bottom 
increases from 0.1589 to 1.0875 .

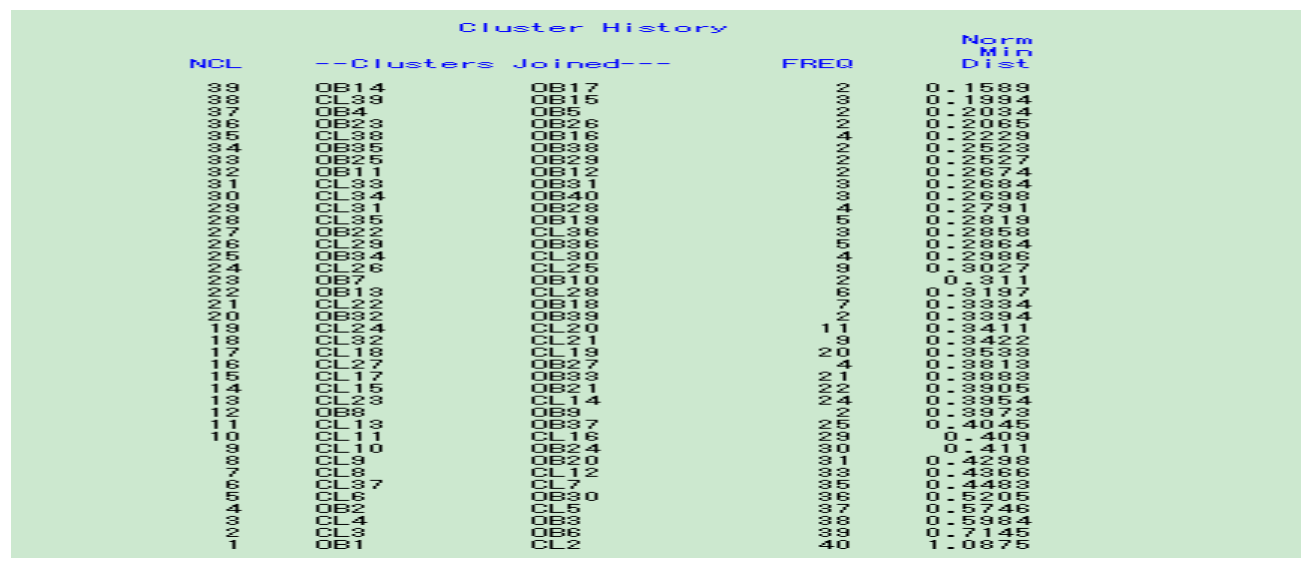

Figure 2 The normal minimum distance of the universities

The arborescence under the shortest distance clustering method is shown in Figure 3.

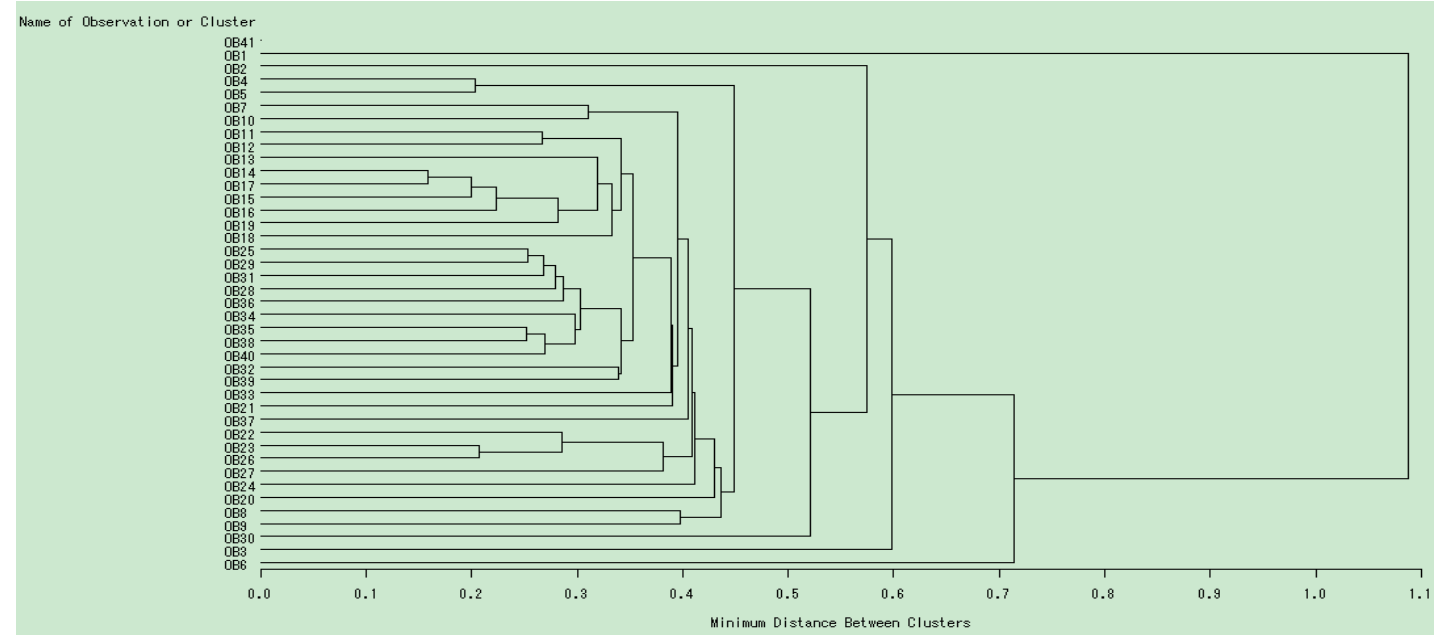

Figure 3 The arborescence under the shortest distance clustering method

\subsection{Conclusion}

According to the clustering arborescence under the group-average cluster method, we divided 40 universities into two types: the two universities ranked as the last two in the Excel table belong to Type 2, while the remaining 38 universities are Type 1 .

\section{The principal component analysis}

Principal component analysis (PCA) is a statistical analysis method which reduces several indicators into a few comprehensive indexes by using dimension reduction technology. By using of this method, we analyzed the quality of the 40 universities in the world in 2005 and summed up the six variables into one or two comprehensive variables to help us analyze the data more easily. From the SAS operating results, we can gain the following information via analyzing. 


\subsection{The extraction of principal components}

\subsubsection{Basic information}

a. The correlation matrix between 10 variables

\begin{tabular}{|c|c|c|c|c|c|c|c|}
\hline \multicolumn{8}{|c|}{ Correlation Matrix } \\
\hline & & $x 1$ & $x^{2}$ & $x^{3}$ & $x 4$ & $\times 5$ & $\times 6$ \\
\hline $\begin{array}{l}x 1 \\
\times 2 \\
\times 3 \\
x 4 \\
x 5 \\
x 6 \\
x 6\end{array}$ & $\begin{array}{l}\text { Score on Alumini } \\
\text { Score on Award } \\
\text { Score on HiCi } \\
\text { Score on NES } \\
\text { Score on SCI } \\
\text { Score on Size }\end{array}$ & $\begin{array}{l}1.0000 \\
0.63533 \\
0.7648 \\
0.3444 \\
0.8030 \\
-.8308\end{array}$ & $\begin{array}{l}0.6353 \\
1.0000 \\
0.9006 \\
0.7856 \\
0.7388 \\
-.7770\end{array}$ & $\begin{array}{l}0.7648 \\
0.9006 \\
1.0000 \\
0.7219 \\
0.8183 \\
-.8161\end{array}$ & $\begin{array}{l}0.3444 \\
0.7856 \\
0.7219 \\
1.0000 \\
0.4024 \\
-.5766\end{array}$ & $\begin{array}{l}0.8030 \\
0.7388 \\
0.8183 \\
0.4024 \\
1.0000 \\
-.7446\end{array}$ & $\begin{array}{l}-.8300 \\
-.7770 \\
-.8161 \\
-.5766 \\
-.7446 \\
1.0000\end{array}$ \\
\hline
\end{tabular}

Figure 4 The correlation matrix between 10 variables

b. Eigenvalues and eigenvectors

\begin{tabular}{c|c|c|c}
\hline Eigenvectors & T1 & T2 & T3 \\
\cline { 1 - 1 } Score on Alumni & 0.393410 & -.493462 & -.340283 \\
\cline { 1 - 1 } Score on Award & 0.431409 & 0.276845 & 0.238879 \\
\cline { 1 - 1 } Score on HiCi & 0.448854 & 0.080797 & 0.194581 \\
\cline { 1 - 1 } Score on N\&S & 0.336267 & 0.725076 & -.156377 \\
\cline { 1 - 1 } Score on SCI & 0.405146 & -.356288 & 0.628191 \\
\cline { 1 - 1 } Score on Size & -.424767 & 0.143696 & 0.608445 \\
\cline { 1 - 2 } Eigenvalues & 4.58763836 & 0.83401292 & 0.27802842 \\
\cline { 1 - 2 } Contribution rate & 0.7646 & 0.1390 & 0.0463 \\
\cline { 1 - 2 } Accumulative & 0.7646 & 0.9036 & 0.9499 \\
\hline contribution rate & & & \\
\hline
\end{tabular}

Table 3 The first three eigenvalues and eigenvectors

We proceed from the correlation matrix for principal component analysis. It can be seen from Table 4-1 that the cumulative contribution rate of the first two principal components has reached $90.36 \%$, and the cumulative contribution rate of the first three principal components is $94.99 \%$, indicating that the first two principal components have contented most of the information, hence the first two principal components are considered to be taken, since they can be a good summary of this set of data.

In this research, the first principal component has approximately equal positive payloads on Score on Score on Alumni x1、Score on Award x2、Score on HiCi x3、 Score on N\&S x4 、Score on SCI x5、Score on Size x6, and thus can be considered as a measurement on the five indicators (except Score on Size) of the universities. The second principal component has a high positive load on the variable Score on $\mathrm{N} \& \mathrm{~S}$ (x4) and a high negative load on the variable Score on Alumni (x1). This principal component can be considered to be suitable for measuring the proportion of the 
university quality parameters.

\subsection{The analysis of principal components}

First of all, 40 universities have been ranked based on the first principal component and the second principal component. The 39th university is -2.29007 after the first principal component scores are ranked in descending order, and the university has all five indicators with scores below 50, in particular its Score on Alumni is 0 point, so the university is the worst in terms of the quality among 40 universities.

On the contrary, the first university has the highest score of 6.11023 , the university's comprehensive level is ranked the first, the evaluation indicators are also outstanding, so the quality evaluation result of this University is excellent. Similarly, it is possible to analyze the case which is sorted by the second principal component.

Scatterplot of the first and second principal components output is shown as in figure 11:
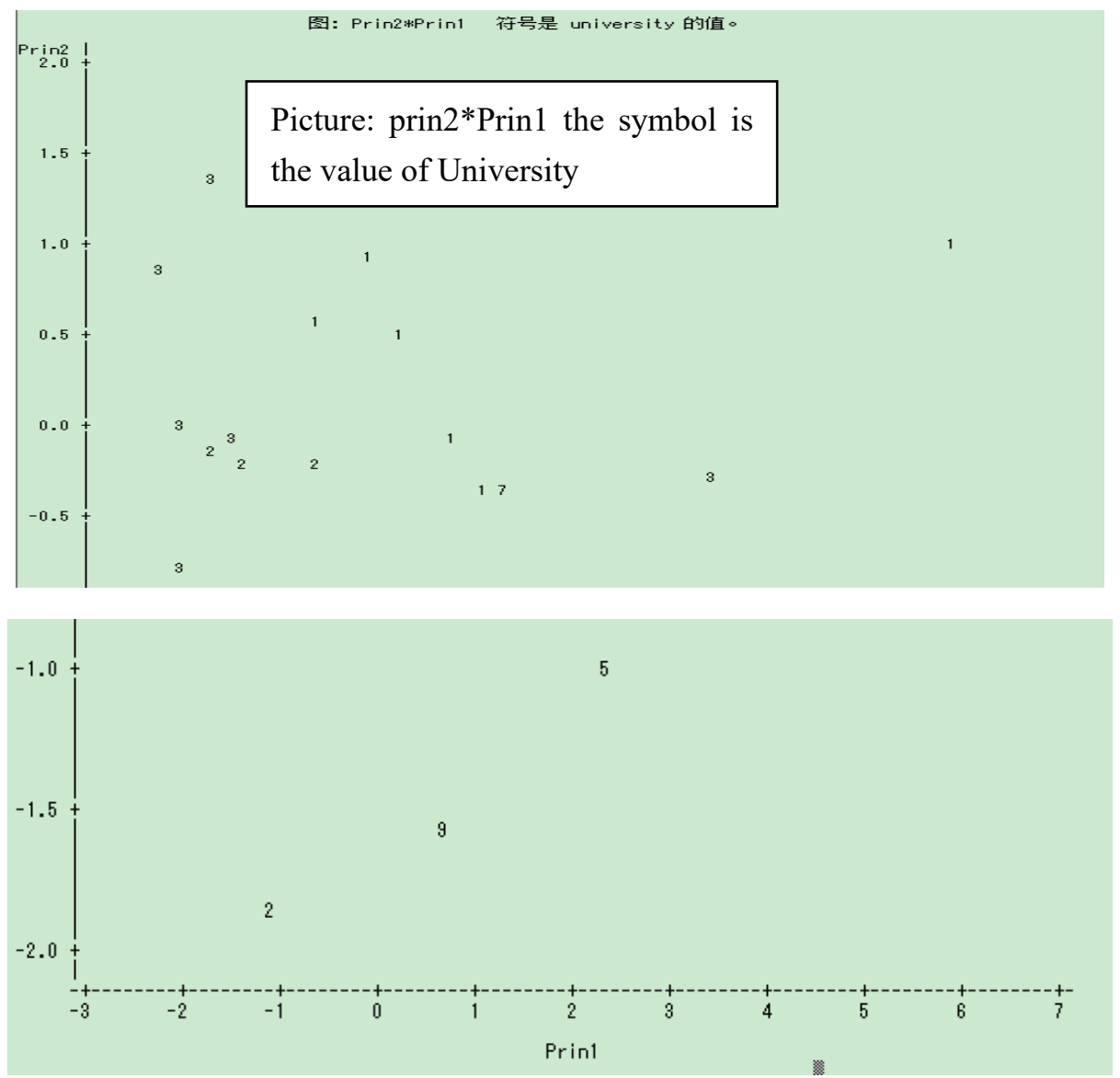

Figure 5 Scatterplot of the first and second principal components output

The scatterplot has a more intuitive description for the N \& S and Alumni of University. Each scatter point has been output by tens of observations, and the duplication of characters can be identified by contracting against SAS output table. 
As it can be seen in the scatterplot, among all observations, the 1st university is on the far right, indicating that the $\mathrm{N} \& \mathrm{~S}$ quality of this university is high. While observing other data shows that the university also has strong comprehensive strength. Thought the observed value 1 is no longer ranks first in the primal component 2 , but it still ranks high, indicating that the Alumni quality of this University is lower than $\mathrm{N} \& \mathrm{~S}$ quality, but it is still in leader place compared with other universities. Observations of the 39th University is at the far left, indicating that it has the lowest $\mathrm{N} \& \mathrm{~S}$ quality in the current year compared to other universities. Similarly, all observed values in the table can be analyzed.

\section{Typical correlation analysis}

Canonical correlation analysis is a statistical method to study the correlation between two groups of variables, which can truly reflect the mutual linear dependency between two groups of variables.

In this part, the data of 40 universities' evaluation indexes in the world are divided into two groups. Score on Alumni, Score on Award, and Score on HiCi are used as a set of quality indicators. Score on N \& S, Score on SCI, Score on Size are selected as another set of quality indicators, and then conduct a typical correlation analysis between the two groups of quality indicators.

\subsection{Typical correlation variables}

In the SAS output of the canonical correlation analysis of data, we can get the mean and standard deviation of score variables of each university group. The correlation coefficient matrix of the two quality indexes and the correlation coefficient matrix between the two groups are as follows:

$$
\begin{aligned}
& R_{x x}=\left\{\begin{array}{lll}
1.0000 & 0.7498 & 0.5476 \\
0.7498 & 1.0000 & 0.5449 \\
0.5476 & 0.5449 & 1.0000 \\
1.0000 & 0.5058 & 0.7091 \\
0.5058 & 1.0000 & 0.1365 \\
0.7091 & 0.1365 & 1.0000
\end{array}\right\} \\
& R_{x y}=\left\{\begin{array}{lll}
0.6392 & 0.4304 & 0.5627 \\
0.6896 & 0.0867 & 0.7210 \\
0.8222 & 0.5736 & 0.5552
\end{array}\right\}
\end{aligned}
$$


Eigenvalue of $R_{x x}^{-1} R_{x y} R_{y y}^{-1} R_{y x}$ is $\lambda_{1}=3.5231, \lambda_{2}=0.9049, \lambda_{3}=0.0470$.

The corresponding raw coefficients are shown in figure 19.

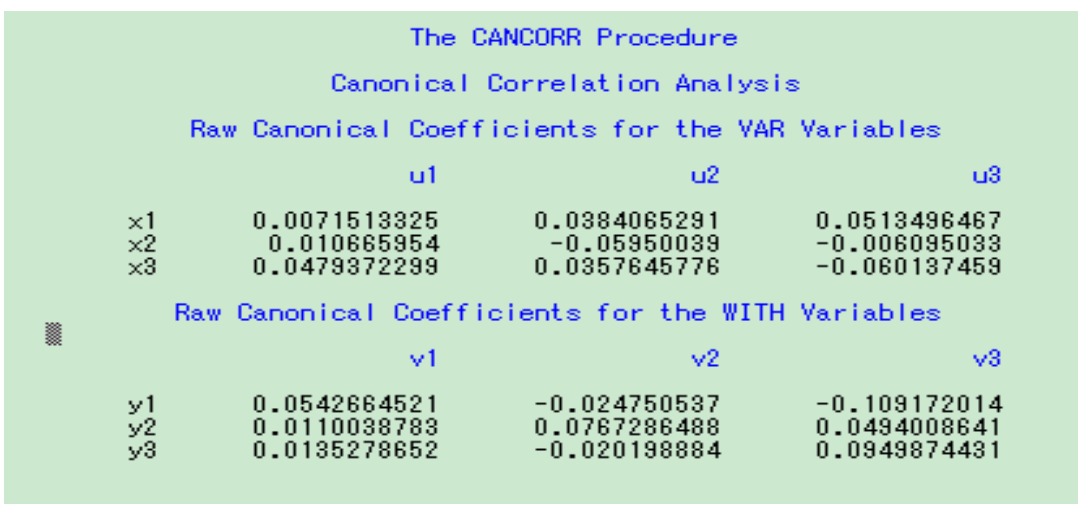

Figure 6 The raw coefficients

From this we can get the first pair of typical variables:

$$
\begin{aligned}
& \mathrm{u}_{1}=\widehat{a}_{1}^{T} X=0.007151 \mathrm{X}_{1}+0.010666 \mathrm{X}_{2}+0.047937 \mathrm{X}_{3} \\
& \mathrm{v}_{1}=\widehat{b}_{1}^{T} Y=0.054266 \mathrm{Y}_{1}+0.011004 \mathrm{Y}_{2}+0.013528 \mathrm{Y}_{3}
\end{aligned}
$$

Similarly, the second and third pairs of typical variables can be obtained. Typical canonical correlation coefficients are shown in figure 20:

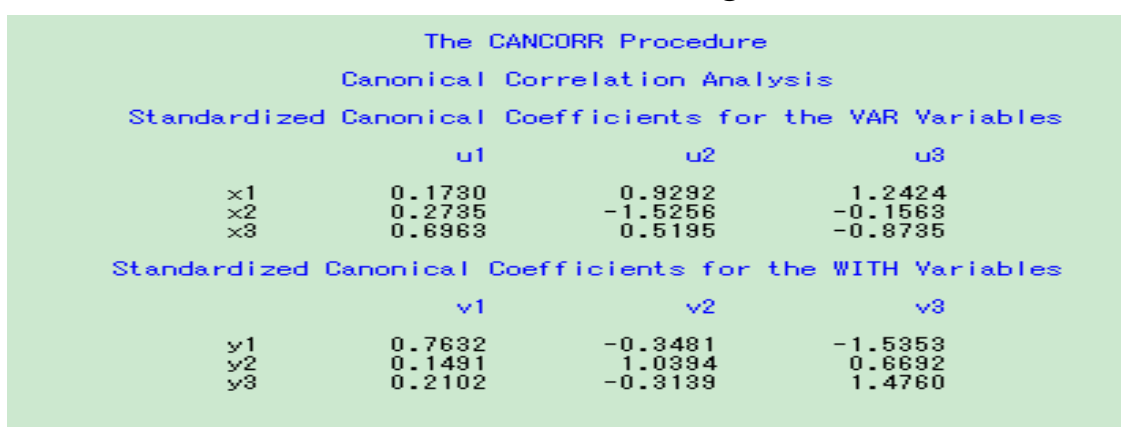

Figure 7 Typical canonical correlation coefficients

We can get the first pair of typical variables:

$$
\begin{aligned}
& \mathrm{u}^{*}{ }_{1}=\widehat{a}^{* T} X^{*}=0.1730 \mathrm{X}^{*}{ }_{1}+0.2735 \mathrm{X}^{*}{ }_{2}-0.6963 \mathrm{X}^{*}{ }_{3} \\
& \mathrm{v}^{*}{ }_{1}=\widehat{b}_{1}^{* T} Y^{*}=0.7632 \mathrm{Y}^{*}{ }_{1}+0.1491 \mathrm{Y}^{*}{ }_{2}+0.2102 \mathrm{Y}_{3}^{*}
\end{aligned}
$$

Similarly, the second and third pairs of typical variables can be obtained. 


\subsection{The test of the typical correlation coefficient significance}

Next, we perform a canonical correlation analysis:

Establish the null hypothesis $H_{0}: \rho_{1}=\rho_{2}=\ldots=\rho_{m}=0$, (10) that the alternative assumes $H_{1}: \rho_{1}, \rho_{2}, \ldots ., \rho_{m}$, and at least one of them is not zero. Construct likelihood ratio statistics $\Lambda=\prod_{i=1}^{m}\left(1-r_{i}^{2}\right)$, (11) for sufficient large n, when $H_{0}$ established, the statistic $Q=-\left[n-\frac{1}{2}(p+q+3)\right] \ln \Lambda$

) nearly obeyed the distribution of $\chi^{2}{ }_{\text {of }}^{p q}$. At a given level of significance $=0.05$, if $^{Q} \geq \chi_{\partial}^{2}(p q)$, the original hypothesis is rejected, the correlation of the representative variables $u_{1}$ and $v_{1}$ is significant, otherwise the typical correlation coefficient is not significant.

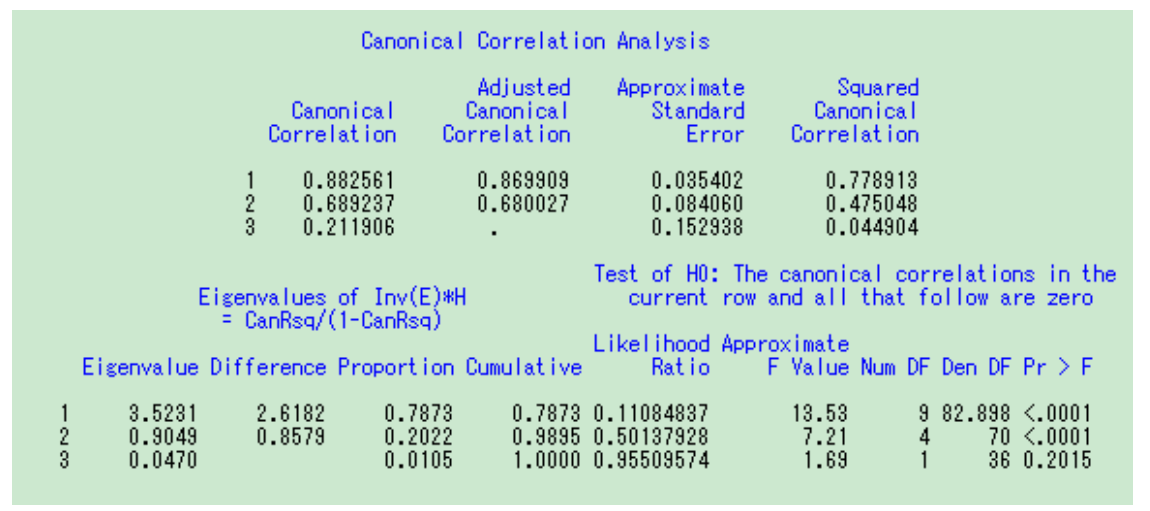

Figure8 Results of canonical correlation analysis

As it can be seen from figure 21, v1 and $\mathrm{u} 1$, u2, u3 of the typical correlation coefficients are not 0 , they are respectively $0.882561,0.689237$ and 0.211906 .

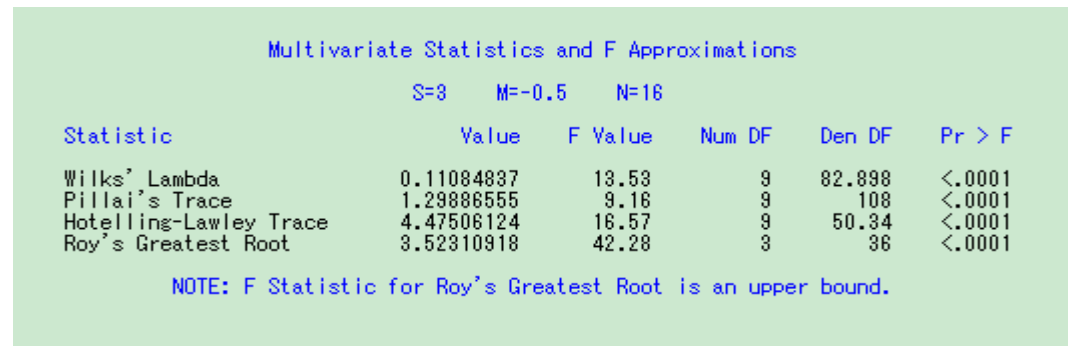

Figure 9 Multivariate statistics and $\mathrm{F}$ approximations 
As shown in figure 22, p values tested by Wilks' Lambda, Pillai's Trace, Hotelling-Lawley Trace and Roy's Greatest Root are less than 0.0001. Thus, the correlation of the visible indicators is significant based on the above analysis. As a result, we can find that it is necessary to evaluate Alumni, Award, HiCi, N \& S, SCI, Size as the quality indicators.

\subsection{Brief Summary}

According to the results of Canonical Correlation Analysis and the actual situation of each university, there is a strong correlation among Alumni, Award, HiCi, N \& S, SCI and Size indicators which represent the overall quality of the university. Therefore, in the process of perfecting themselves, the university should not only focus on their single-level of their own access to the honor or the size. And for people to choose the school, besides the focus of whether the school is of a certain level of excellency or deficiency, the comprehensive aspects of the certain university should also be concerned. By doing this, on the one hand, each university can better balance the development of all directions when planning the future development. On the other hand, students can objectively choose the school with excellent comprehensive strength.

\section{Conclusion}

After multivariate analysis, we can find that university quality assessment plays an important role in measuring university comprehensive level. Although the selection of this sample size represents only index score of a year, it reflects the quality of scientific assessment of the University to a certain extent.

We are able to analyze the quality of the universities in each group, and we can classify the two groups into two types, namely, the excellent type and the general type, so as to judge the comprehensive quality of the university objectively. In addition, it is important to choose principal indicators for judgment, and to conduct the extreme value analysis, by which to comprehensively assess the quality of the university. One thing need extra attention that although these indicators are designed very scientifically, in discriminant analysis, we still found wrong classification of the universities, hence this quality evaluation system is worth to be further improved, so as to provide a more reasonable comprehensive quality reflection of the University.

\section{Reference}

[1] Wang Xue min (2004), 'Applied Multivariate Analysis', Shanghai University of Finance and Economics Press.

[2] ZHOU Gang, CAO Qun (2001), 'Quality Evaluation Scheme of American Universities’, Higher Science Education, No. 3. 
[3] ZHOU Guang li (2007), 'Popularization of Higher Education and Quality Predicament of Research University: example from Canada', Modern University Education, No. 6.

[4] Arild Tjeldvoll, LUO Dan, GAO Xiao jie (2004), 'Globalization and University Quality Improvement: the Effect of Globalization to the University Service Quality and Organization', Fudan Education Forum, Vol. 2, No.3.

[5] ZHANG Zhi gang, HAN Yan hui, 'ISO9000: System Worth Reference for University Quality Evaluation', Journal Beijing University of Chemical Technology, No.3.

[6] SHEN Yu shun, CHEN Yu kun (2002),'Promoting University Teaching Quality through Evaluation', Journal of China University of Geosciences (Social Sciences Edition)', G642.4. 